This is the peer reviewed version of the following article:

Koch, S. and Pettigrew, S. and Minto, C. and Slevin, T. and Strickland, M. and Lin, C. and Jalleh, G. 2016. Trends in sun-protection behaviour in Australian adults 2007-2012.

Australasian Journal of Dermatology,

which has been published in final form at http://doi.org/10.1111/ajd.12433

This article may be used for non-commercial purposes in accordance with Wiley Terms and Conditions for Self-Archiving at

http://olabout.wiley.com/WileyCDA/Section/id-828039.htm|\#terms 
Running head: TRENDS IN SUN-PROTECTION BEHAVIOURS

Trends in Sun-Protection Behaviours in Australian Adults 2007-2012

\author{
Severine $\operatorname{Koch}^{1,2}, \mathrm{PhD}$ \\ Simone Pettigrew ${ }^{1}, \mathrm{PhD}$ \\ Carolyn Minto², BHS \\ Terry Slevin ${ }^{1,2}, \mathrm{MPH}$ \\ Mark Strickland $^{2}$, BA \\ Chad $\operatorname{Lin}^{1}, \mathrm{PhD}$ \\ Geoffrey Jalleh ${ }^{1}, \mathrm{PhD}$ \\ ${ }^{1}$ Curtin University \\ ${ }^{2}$ Cancer Council Western Australia
}

Correspondence: Severine Koch, Western Australian Cancer Prevention Research Unit (WACPRU), School of Psychology and Speech Pathology, Curtin University, Kent Street, Bentley, WA 6102, Australia. Email: severine.koch@curtin.edu.au.

Conflict of interest statement: The authors declare that there are no conflicts of interest.

Funding: The Cancer Council Western Australia is funded by the Western Australian Department of Health to deliver and evaluate the SunSmart health promotion campaign. 


\begin{abstract}
Background Almost all skin cancers are the result of overexposure to ultraviolet (UV) radiation and could be prevented by adhering to a number of simple behavioural guidelines to minimise exposure to the sun. The present study examined trends in sun-protection behaviours among adults living in Western Australia - a region with high levels of UV radiation.
\end{abstract}

Methods During five summers from 2007/08 to 2011/12, 2076 Western Australian adults participated in annual, cross-sectional telephone surveys that assessed how often they engaged in a range of sun-protection behaviours (seeking shade, staying inside, and wearing a hat, protective clothing, sunscreen, or sunglasses).

Results Apart from an increase in sunscreen use and a consistently high use of sunglasses, most sun-protection behaviours remained stable at moderate levels during the 5-year period. Seeking shade, staying inside, and wearing a hat were all practised at levels ranging between 'sometimes' and 'usually' on sunny days in summer during peak UV hours, with little to no variability across survey years. Wearing protective clothing was the least frequently enacted behaviour across all survey years and was significantly lower in the most recent survey year relative to baseline.

Conclusions Further efforts are required to encourage greater enactment of sun-protection behaviours, especially regarding the use of protective clothing and seeking shade during periods of high UV radiation.

Keywords: skin cancer, adults, prevention, protection, trends, sun 


\section{Trends in Sun-Protection Behaviours in Australian Adults 2007-2012}

Most research on behaviours relating to skin cancer has been conducted in Australia and the US, reflecting the high prevalence of the disease in these two countries. ${ }^{1,2}$ At least two in three Australians and one in five Americans will develop skin cancer before the age of $70 .{ }^{3,4}$ Exposure of the skin to high levels of ultraviolet (UV) radiation has been identified as the major cause of skin cancer ${ }^{5}$, placing those living in countries with very high levels of solar UV radiation, such as Australia and the US, at an increased risk. ${ }^{6}$

Despite Australia's reputation as melanoma capital of the world ${ }^{7}$, it has been put forward as a textbook example for successful population-wide skin cancer prevention efforts and a guiding model for other high-prevalence countries. ${ }^{7,8}$ Sun-protection mass media campaigns have run in Australia since the early 1980s ${ }^{9}$, and school-based educational programs and policies have been in place since the mid-1990s. ${ }^{10}$ Consistent and continued communication of sun-related public-health messages through health professionals, schools, employers, and Cancer Councils, and the promotion of easily implementable protection measures such as shade, have resulted in sun protection becoming an integral part of daily life. ${ }^{7}$ Unlike the strong emphasis on sunscreen use in sun-protection messages disseminated in other countries ${ }^{11}$, Australian media campaigns have long promoted a combination of different sun-protection measures, as reflected in the message 'slip, slop, slap', which refers to the use of protective clothing, sunscreen, and headwear. ${ }^{9}$

Sun-related public health strategies can only be regarded as successful in as far as they translate into sustained changes in sun-protection behaviours at a population level. Among Australians aged under 45 years, skin cancer rates are declining ${ }^{12,13}$, providing evidence for 
positive changes in sun-protection behaviours. Previous longitudinal studies of adult sunprotection behaviours in Australia, the US, and elsewhere have shown favourable trends for sunscreen usage rates and, more recently, staying indoors. ${ }^{14-19}$ Other sun-protection behaviours (such as staying in the shade or wearing sunglasses, hats, and long clothing) have either shown no consistent improvements over time or decreased in more recent years. ${ }^{14,15,19}$

Direct comparisons between studies and countries are difficult due to differences in measures employed to assess engagement in sun-protection behaviours and the use of state versus national samples. Nevertheless, insights from previous longitudinal studies in Australia suggest that drastic improvements in sun-protection behaviours were achieved up to the mid1990s, with smaller fluctuations and greater relative stability since. ${ }^{15,18}$ Based on these trends over time, it appears that sun-protection behaviours have reached a plateau after a steep upward trend in the past.

To confirm this observation and provide a more comprehensive account of trends in sunprotection behaviours, the present study analysed data from five consecutive summers in Western Australia (2007/08 to 2011/12). Western Australia has one of the highest rates of skin cancer risk in the country due to high levels of solar UV radiation. ${ }^{6}$ The yearly total solar UV radiation in Perth (the capital city of Western Australia) amounts to 12234 standard erythema doses (SEDs), which is two to three times the yearly doses in various locations across Europe. ${ }^{6}$ Sustained monitoring of sun-protection behaviours is needed in Western Australia to identify opportunities for continued improvement in sun-protection practices to reduce the high risk of skin cancer. 
The focus of the present study was on behaviours that reduce the risk of overexposure to UV radiation when outdoors (seeking shade and wearing a hat, protective clothing, sunscreen, or sunglasses), as well as the complete avoidance of UV radiation by staying inside during peak hours. Based on previous trends, it was predicted that sunscreen use and staying indoors would continue to increase at moderate levels, while other sun-protection behaviours would either stabilise or slightly decrease.

\section{Method}

The study received approval from the Curtin University Human Research Ethics Committee. As part of an ongoing cross-sectional study, telephone surveys were conducted in the summers of $2007 / 08$ to $2011 / 12$ inclusive. The aim of the broader study was to evaluate a long-running SunSmart sun-protection campaign in Western Australia to assess campaign effectiveness. As such, the survey included items relating to awareness of the campaign, understanding of the campaign message, and any changes in behaviour resulting from exposure. The total usable sample consisted of 2076 adults aged 18-45 years who were selected via random digit dialling. The age range reflects the importance of prevention in the younger years for reducing the lifetime risk of skin cancer, and hence the focus in sunprotection campaigns on younger audiences. Quotas were used to recruit equal numbers of males and females, and proportionate numbers of respondents within the age categories 1829, 30-39, and 40-45 years. Table 1 summarises the number of respondents by gender, age category, and skin colour. Respondents reported their skin colour (without a tan) according to the seven categories 'very fair', 'fair', 'medium', 'olive', 'dark', 'very dark', and 'black'. 
Insert Table 1 about here

\section{Meas ure s of Sun-Protection Behaviours}

To assess the frequency of practising commonly recommended sun-protection behaviours, respondents were asked to indicate on 5-point Likert scales how often they would engage in six different sun-protection behaviours (seeking shade, staying inside, and wearing a hat, protective clothing, sunscreen, or sunglasses) during sunny days in summer between 10am and $2 \mathrm{pm}$. Response categories were never (1), rarely (2), sometimes (3), usually (4), and always (5). The five items assessing outdoor protection behaviours included the qualification 'when being in the sun for an hour or more'.

\section{Statis tical Analysis}

Ordinal regression analyses were conducted due to the ordinal response categories used to indicate the frequency of engaging in sun-protection behaviours. To assess trends in protection practices over time, separate analyses were conducted for each of the sunprotection behaviours (wearing a hat, protective clothing, sunscreen, or sunglasses, seeking shade, staying inside) as dependent variables and survey year (2007/08, 2008/09, 2009/10, 2010/11, 2011/12) as the predictor variable, controlling for the effects of age, gender, skin colour, and other protection behaviours. The frequencies of sun-protection behaviours in each subsequent year were compared with frequencies in the baseline year 2007/08. Regression coefficients were transformed into odds ratios for ease of interpretation. A significance level of .05 was used for all reported analyses.

\section{Results}




\section{Sun-Protection Behaviours}

Table 2 reports means, standard errors, adjusted odds ratios (AORs) with $95 \%$ confidence intervals, and $p$-values for the six sun-protection behaviours.

\section{Insert Table 2 about here}

In all survey years, wearing sunglasses was the sun-protection behaviour respondents engaged in most frequently (average $M=4.24$ ), with sunscreen use ranking second (average $M=3.83$ ). In terms of response categories, sunglasses were used at a frequency ranging between 'usually' and 'always' on sunny days in summer between 10am and 2pm when outdoors for an hour or more. Sunscreen was used at a frequency ranging between 'sometimes' and 'usually' (see Figure 1).

Wearing protective clothing was the behaviour practiced least frequently across all survey years (average $M=2.85$ ). The average frequency of wearing covering clothes on sunny days in summer between 10am and 2pm when outdoors for an hour or more was just below 'sometimes'.

\section{Insert Figure 1 about here}

Compared to baseline, the frequency of wearing a hat and seeking shade remained unchanged in all subsequent survey years, while staying inside and wearing protective clothing and sunglasses remained unchanged in most survey years. In the most recent survey year, wearing protective clothing was the only sun-protection behaviour that was practised less frequently 
compared to baseline $(A O R=0.75)$. Sunscreen was used significantly more frequently relative to baseline in all subsequent survey years (average $A O R=1.39$ ).

In terms of individual differences controlled for in the above analyses, skin type was significantly associated with the frequency of using sunscreen and seeking shade.

Respondents with lighter skin types were found to engage in these behaviours more frequently than respondents with darker skin types $(\beta=-.22, p<.001$ for sunscreen; $\beta=-.10$, $p=.013$ for shade). Older age was significantly associated with increased use of hats $(\beta=$ $.66, p<.001)$, sunglasses $(\beta=.44, p<.001)$, and shade $(\beta=.19, p=.002)$, and more frequently staying inside $(\beta=.19, p=.002)$. Men reported wearing hats $(\beta=.71, p<.001)$ and covering clothes $(\beta=.25, p=.003)$ more frequently than women, while women reported wearing sunscreen $(\beta=.83, p<.001)$, sunglasses $(\beta=.64, p<.001)$, and staying inside $(\beta=$ $.57, p<.001)$ or in the shade $(\beta=.45, p<.001)$ more often than men.

\section{Discussion}

The present study investigated changes in adult sun-protection behaviours over a 5-year time period $(2007 / 08-2011 / 12)$. The context of the study was Western Australia, where enactment of sun-protection behaviours in summer is critical due to very high levels of solar UV radiation. ${ }^{6}$ In all survey years, wearing sunglasses was the most commonly practised sunprotection behaviour, followed by using sunscreen. This general pattern of results is in line with previous studies identifying either (i) use of sunglasses as the most commonly used sunprotection behaviour ${ }^{19,20}$ or (ii) use of sunscreen as the most common behaviour when the frequency of wearing sunglasses was not assessed. ${ }^{11,14,21-23}$ No notable changes in sunglass 
use were observed, possibly reflecting the fact that these items are worn at a frequency that leaves little room for improvement. In addition, sunglasses are often worn for reasons other than sun protection ${ }^{20}$, including fashion and vision, which may explain their high and continuing popularity.

Sunscreen was used more frequently over time, which is a desirable development in terms of skin protection and skin cancer prevention. ${ }^{24}$ However, although the effectiveness of sunscreen in preventing skin cancer has been clearly demonstrated ${ }^{24}$, it needs to be used correctly to provide the expected level of protection. ${ }^{17}$ People often use too little sunscreen, fail to apply it to all exposed skin, reapply inadequately, and/or view sunscreen as a substitute for other sun-protection practices rather than as an adjunct. ${ }^{11,14}$ The relatively heavy reliance of Western Australians on sunscreen use as a sun-protection strategy indicates that information about correct application needs to be strongly emphasised in health promotion messages, along with advice about alternative or complementary forms of protection such as protective clothing and shade. ${ }^{17}$

Apart from an increase in sunscreen use and consistently high use of sunglasses, most sunprotection behaviours remained stable at moderate levels. Seeking shade, staying inside, and wearing a hat were all practised at levels ranging between 'sometimes' and 'usually' during peak UV hours, with little to no variability across survey years. Wearing protective clothing was the least frequently enacted sun-protection behaviour, with average frequencies of less than 'sometimes'. The already low rates of wearing protective clothing significantly decreased relative to baseline in the last survey year, suggesting a need to address this sunprotection behaviour in particular given that it provides a simple and effective way to protect the skin from sun exposure. Factors contributing to low levels of protective clothing use may 
include a lack of comfort or excessive sweating when wearing covering clothes in warm ambient conditions. Wearing clothes with a high UV protection factor that are made from lightweight and moisture-absorbing fabric may be an acceptable compromise between sunprotection needs and comfort. ${ }^{25}$ Further research would be of benefit to identify ways to promote long clothing as a means to protect the skin from UV radiation.

Among the sun-protection behaviours that remained mostly unchanged over the 5-year survey period, seeking shade and staying inside were enacted at similar frequencies. These two behaviours constitute two different classes of protection measures - one that involves protecting the skin from sun exposure when outside and one that involves complete avoidance of sun exposure by staying indoors. To take this distinction into account, the survey items assessing outdoor protection behaviours included the qualification 'when being in the sun for an hour or more'. Due to this wording difference, it is difficult to draw direct comparisons between the frequency of engaging in outdoor protection behaviours and staying indoors. The outdoor context incurs an immediate risk and greater urgency in terms of sunprotection requirements, and there is no upper limit to what constitutes ideal outdoor protection because maximum sun protection is encouraged at all times during peak UV hours. By comparison, by staying inside individuals effectively protect their skin from UV damage, but this may have negative unintended consequences. The greater engagement in sedentary behaviours when indoors, such as television viewing and other screen-based activities, has been associated with negative health outcomes in both adults and children. ${ }^{26,}{ }^{27}$ Finding a balance between the risks and benefits of various health-related activities is an ongoing challenge. As a consequence, promoting outdoor activities during non-peak UV times may maximise beneficial health outcomes by decreasing the risk of sun damage to the skin, increasing activity levels ${ }^{27}$, and providing adequate amounts of natural Vitamin D. ${ }^{28}$ 
A number of limitations of this study need to be considered, including the use of self-report measures to assess the frequency of engaging in sun-protection behaviours. Relying on selfreport may distort results due to poor recall or socially desirable responses. ${ }^{29}$ However, selfreported sunscreen use has been shown to correspond with objective measurements of sunscreen use ${ }^{29}$, supporting the validity of self-reports of sun-protection behaviours. Second, temperature or other weather conditions were not controlled for in the present investigation. Summers in the highly populated areas of Western Australia tend to be invariably hot and dry, with average UV radiation levels of 11 or higher at noon during the summer months, indicating that the influence of changes in weather conditions would be negligible. Finally, as the focus in the present study was on trends in sun-protection behaviours over time, no distinction was made between the various contexts in which sun exposure may occur. For instance, outdoor workers are usually restricted in their ability to use the full range of sunprotection measures, especially seeking shade, placing this group at an increased risk of developing skin cancer. ${ }^{30}$ As a consequence, knowing under which circumstances respondents usually spend time in the sun during peak UV-times (e.g., work, leisure, sports) would provide further useful insights into context effects and the feasibility of sun-protection behaviours across a range of settings. This would require a more comprehensive instrument that includes context variables and sun exposure during working hours, as well as the extent to which sun-protection measures are practiced according to recommendations (e.g., amount of sunscreen used and timing of sunscreen application).

In summary, despite slight fluctuations in use of sunscreen and protective clothing, sunprotection behaviours among Western Australian adults remained relatively stable during the 5-year study period from $2007 / 08$ to $2011 / 12$. In contrast to the drastic improvements in sun- 
protection behaviours observed in earlier years, these findings indicate that the frequency of engaging in sun-protection behaviours has plateaued. However, observed frequencies of most sun-protection behaviours were still moderate and further efforts are required to encourage higher enactment rates. Strategies are especially needed to promote use of shade and overcome reservations regarding the use of protective clothing during periods of high UV radiation. The former particularly applies to younger age groups and males, while the latter is especially relevant for females. 


\section{References}

1. Keeney S, McKenna H, Fleming P, McIlfatrick S. Attitudes, knowledge and behaviours with regard to skin cancer: A literature review. Eur J Oncol Nurs. 2009; 13: 29-35.

2. Perera E, Gnaneswaran N, Staines C, Win AK, Sinclair R. Incidence and prevalence of non-melanoma skin cancer in Australia: A systematic review. Australas J Dermatol. 2015.

3. Staples MP, Elwood M, Burton RC, Williams JL, Marks R, Giles GG. Non-melanoma skin cancer in Australia: the 2002 national survey and trends since 1985. Med J Aust. 2006; 184: 6-10.

4. Stern RS. Prevalence of a history of skin cancer in 2007: Results of an incidence-based model. Arch Dermatol. 2010; 146: 279-82.

5. Greinert R, De Vries E, Erdmann F, Espina C, Auvinen A, Kesminiene A, Schüz J. European Code against Cancer 4th edition: Ultraviolet radiation and cancer. Cancer Epidemiol. 2015.

6. Gies P. Australia has more than enough solar UV radiation. Clin Exp Optom. 2003; 86: 7173.

7. Corbyn Z. Lessons from a sunburnt country. Nature. 2014; 515: S114-S6.

8. Lazovich D, Choi K, Vogel RI. Time to get serious about skin cancer prevention. Cancer Epidemiol Biomarkers Prev. 2012; 21: 1893-901.

9. Montague M, Borland R, Sinclair C. Slip! Slop! Slap! and SunSmart, 1980-2000: Skin cancer control and 20 Years of population-based campaigning. Health Educ Behav. 2001; 28: 290-305.

10. Dobbinson S, Peipers A, Reading D, Sinclair C. A national approach to skin cancer prevention: the National SunSmart Schools Program. Med J Aust. 1998; 169: 513-4. 
11. Linos E, Keiser E, Fu T, Colditz G, Chen S, Tang JY. Hat, shade, long sleeves, or sunscreen? Rethinking US sun protection messages based on their relative effectiveness. Cancer Causes Control. 2011; 22: 1067-71.

12. Erdmann F, Lortet-Tieulent J, Schuz J, Zeeb H, Greinert R, Breitbart EW, Bray F. International trends in the incidence of malignant melanoma 1953-2008 - are recent generations at higher or lower risk? Int J Cancer. 2013; 132: 385-400.

13. Olsen CM, Williams PF, Whiteman DC. Turning the tide? Changes in treatment rates for keratinocyte cancers in Australia 2000 through 2011. J Am Acad Dermatol. 2014; 71: 21-6.

14. Bandi P, Cokkinides VE, Weinstock MA, Ward E. Sunburns, sun protection and indoor tanning behaviors, and attitudes regarding sun protection benefits and tan appeal among parents of U.S. adolescents-1998 compared to 2004. Pediatr Dermatol. 2010; 27: 9-18.

15. Dobbinson SJ, Wakefield MA, Jamsen KM, Herd NL, Spittal MJ, Lipscomb JE, Hill DJ. Weekend sun protection and sunburn in Australia: Trends (1987-2002) and sssociation with SunSmart television advertising. Am J Prev Med. 2008; 34: 94-101.

16. Gavin A, Boyle R, Donnelly D, Donnelly C, Gordon S, McElwee G, O’Hagan A. Trends in skin cancer knowledge, sun protection practices and behaviours in the Northern Ireland population. Eur J Public Health. 2012; 22: 408-12.

17. Ghiasvand R, Lund E, Edvardsen K, Weiderpass E, Veierod MB. Prevalence and trends of sunscreen use and sunburn among Norwegian women. Br J Dermatol. 2015; 172: 475-83.

18. Makin JK, Warne CD, Dobbinson SJ, Wakefield MA, Hill DJ. Population and age-group trends in weekend sun protection and sunburn over two decades of the SunSmart programme in Melbourne, Australia. Br J Dermatol.2013; 168: 154-61. 
19. Volkov A, Dobbinson S, Wakefield M, Slevin T. Seven-year trends in sun protection and sunburn among Australian adolescents and adults. Aust N Z J Public Health. 2013; 37: $63-9$.

20. Weinstock MA, Rossi JS, Redding CA, Maddock JE, Cottrill SD. Sun protection behaviors and stages of change for the primary prevention of skin cancers among beachgoers in Southeastern New England. Ann Behav Med. 2000; 22: 286-93.

21. Devos SA, Baeyens K, Van Hecke L. Sunscreen use and skin protection behavior on the Belgian beach. Int J Dermatol. 2003; 42: 352-6.

22. Schofield PE, Freeman JL, Dixon HG, Borland R, Hill DJ. Trends in sun protection behaviour among Australian young adults. Aust N Z J Public Health. 2001; 25: 62-5.

23. Stanton WR, Janda M, Baade PD, Anderson P. Primary prevention of skin cancer: A review of sun protection in Australia and internationally. Health Promot Internation. 2004; 19: 369-78.

24. Green AC, Williams GM, Logan V, Strutton GM. Reduced Melanoma After Regular Sunscreen Use: Randomized Trial Follow-Up. J Clin Oncol. 2011; 29: 257-63.

25. Hoffmann K, Kaspar K, Gambichler T, Altmeyer P. In vitro and in vivo determination of the UV protection factor for lightweight cotton and viscose summer fabrics: A preliminary study. J Am Acad Dermatol. 2000; 43: 1009-16.

26. LeBlanc AG, Katzmarzyk PT, Barreira TV, Broyles ST, Chaput JP, Church TS, et al. Correlates of total sedentary time and screen time in 9-11 year-old children around the world: The international study of childhood obesity, lifestyle and the environment. PLoS One. 2015; 10.

27. Thorp AA, Owen N, Neuhaus M, Dunstan DW. Sedentary behaviors and subsequent health outcomes in adults: A systematic review of longitudinal studies, 1996-2011. Am J Prev Med. 2011; 41: 207-15. 
28. Holick MF. Vitamin D deficiency. NEngl J Med. 2007; 357: 266-81.

29. Glanz K, McCarty F, Nehl EJ, O'Riordan DL, Gies P, Bundy L, Locke AE, Hall DM. Validity of self-reported sunscreen use by parents, children, and lifeguards. Am J Prev Med. 2009; 36: 63-9.

30. Bauer A, Ronsch H, Hault K, Puschel A, Knuschke P, Beissert S. Sun exposure:

perceptions and behaviours in outdoor workers. Br J Dermatol. 2014; 171: 1570-2. 
Table 1

Gender, Age, and Skin Colour of Respondents $(N=2076)$

\begin{tabular}{|c|c|c|}
\hline & $n$ & $\%$ \\
\hline \multicolumn{3}{|l|}{ Gender } \\
\hline Male & 1024 & 49.3 \\
\hline Female & 1052 & 50.7 \\
\hline \multicolumn{3}{|l|}{ Age } \\
\hline $18-29$ years & 966 & 46.5 \\
\hline 30-39 years & 723 & 34.8 \\
\hline 40-45 years & 387 & 18.6 \\
\hline \multicolumn{3}{|l|}{ Skin colour } \\
\hline Very fair & 297 & 14.3 \\
\hline Fair & 703 & 33.9 \\
\hline Medium & 545 & 26.3 \\
\hline Olive & 439 & 21.1 \\
\hline Dark & 76 & 3.7 \\
\hline Very dark & 11 & 0.5 \\
\hline Black & 5 & 0.2 \\
\hline
\end{tabular}


Table 2

Trends in Enactment of Sun-Protection Behaviours from 2007/08 to 201 1/12

\begin{tabular}{|c|c|c|c|c|c|}
\hline Behaviour & $\begin{array}{l}2007 / 08 \\
N=517\end{array}$ & $\begin{array}{l}2008 / 09 \\
N=457\end{array}$ & $\begin{array}{l}2009 / 10 \\
N=404\end{array}$ & $\begin{array}{l}2010 / 11 \\
N=393\end{array}$ & $\begin{array}{l}2011 / 12 \\
N=305\end{array}$ \\
\hline \multicolumn{6}{|l|}{ Wear a hat } \\
\hline $\operatorname{Mean}\left(S E^{\mathrm{a}}\right)$ & $3.55(.05)$ & $3.44(.06)$ & $3.41(.06)$ & $3.42(.06)$ & $3.46(.07)$ \\
\hline Adjusted odds ratio & 1 & 0.86 & 0.83 & 0.81 & 0.88 \\
\hline $95 \% \mathrm{CI}^{\mathrm{b}}$ & & $0.69-1.09$ & $0.65-1.05$ & $0.63-1.03$ & $0.68-1.14$ \\
\hline$p$-value & & .215 & .115 & .079 & .318 \\
\hline \multicolumn{6}{|l|}{ Wear covering clothes } \\
\hline Mean $\left(S E^{\mathrm{a}}\right)$ & $2.90(.05)$ & $2.85(.06)$ & $2.87(.06)$ & $2.92(.06)$ & $2.71(.07)$ \\
\hline Adjusted odds ratio & 1 & 0.93 & 0.95 & 1.00 & 0.75 \\
\hline $95 \% \mathrm{CI}^{\mathrm{b}}$ & & $0.74-1.16$ & $0.75-1.20$ & $0.79-1.26$ & $0.58-0.96$ \\
\hline$p$-value & & .508 & .678 & .986 & .024 \\
\hline \multicolumn{6}{|l|}{ Wear sunscreen } \\
\hline $\operatorname{Mean}\left(S E^{\mathrm{a}}\right)$ & $3.67(.05)$ & $3.89(0.5)$ & $3.83(0.5)$ & $3.86(.06)$ & $3.92(.06)$ \\
\hline Adjusted odds ratio & 1 & 1.46 & 1.34 & 1.28 & 1.47 \\
\hline $95 \% \mathrm{CI}^{\mathrm{b}}$ & & $1.15-1.84$ & $1.06-1.71$ & $1.00-1.63$ & $1.13-1.91$ \\
\hline$p$-value & & .002 & .016 & .046 & .004 \\
\hline \multicolumn{6}{|l|}{ Wear sunglasses } \\
\hline $\operatorname{Mean}\left(S E^{\mathrm{a}}\right)$ & $4.31(.05)$ & $4.24(.06)$ & $4.25(.06)$ & $4.17(.06)$ & $4.22(.07)$ \\
\hline Adjusted odds ratio & 1 & 0.86 & 0.86 & 0.73 & 0.81 \\
\hline $95 \% \mathrm{CI}^{\mathrm{b}}$ & & $0.66-1.13$ & $0.65-1.13$ & $0.55-0.96$ & $0.60-1.10$ \\
\hline$p$-value & & .281 & .290 & .023 & .174 \\
\hline \multicolumn{6}{|l|}{ Stay in shade } \\
\hline Mean $\left(S E^{\mathrm{a}}\right)$ & $3.59(.03)$ & $3.62(.03)$ & $3.62(.04)$ & $3.64(.04)$ & $3.59(.04)$ \\
\hline Adjusted odds ratio & 1 & 1.05 & 1.09 & 1.12 & 1.02 \\
\hline $95 \% \mathrm{CI}^{\mathrm{b}}$ & & $0.82-1.35$ & $0.84-1.40$ & $0.86-1.44$ & $0.78-1.35$ \\
\hline$p$-value & & .680 & .516 & .402 & .862 \\
\hline \multicolumn{6}{|l|}{ Stay inside } \\
\hline $\operatorname{Mean}\left(S E^{\mathrm{a}}\right)$ & $3.55(.03)$ & $3.43(.03)$ & $3.54(.04)$ & $3.45(.04)$ & $3.48(.04)$ \\
\hline Adjusted odds ratio & 1 & 0.72 & 0.95 & 0.81 & 0.77 \\
\hline $95 \% \mathrm{CI}^{\mathrm{b}}$ & & $0.56-0.92$ & $0.74-1.23$ & $0.63-1.04$ & $0.59-1.02$ \\
\hline$p$-value & & .008 & .717 & .099 & .066 \\
\hline
\end{tabular}

Note. The results of ordinal regression models are presented, adjusting for the effects of age, gender, skin colour, and other protection behaviours. Survey year 2007/08 is the referent year. Means are estimated marginal means with covariates held constant. Frequency of behaviour was classified into the ordinal response categories never (1), rarely (2), sometimes (3), usually (4), and always (5).

${ }^{\mathrm{a}} \mathrm{SE}=$ standard error

${ }^{\mathrm{b}} \mathrm{CI}=$ confidence interval 
Figure 1. Illustration of trends in enactment of sun-protection behaviours from 2007/08 to 2011/12. Values represent estimated marginal means with covariates held constant.

Frequency of behaviour was classified into the ordinal response categories never (1), rarely (2), sometimes (3), usually (4), and always (5).

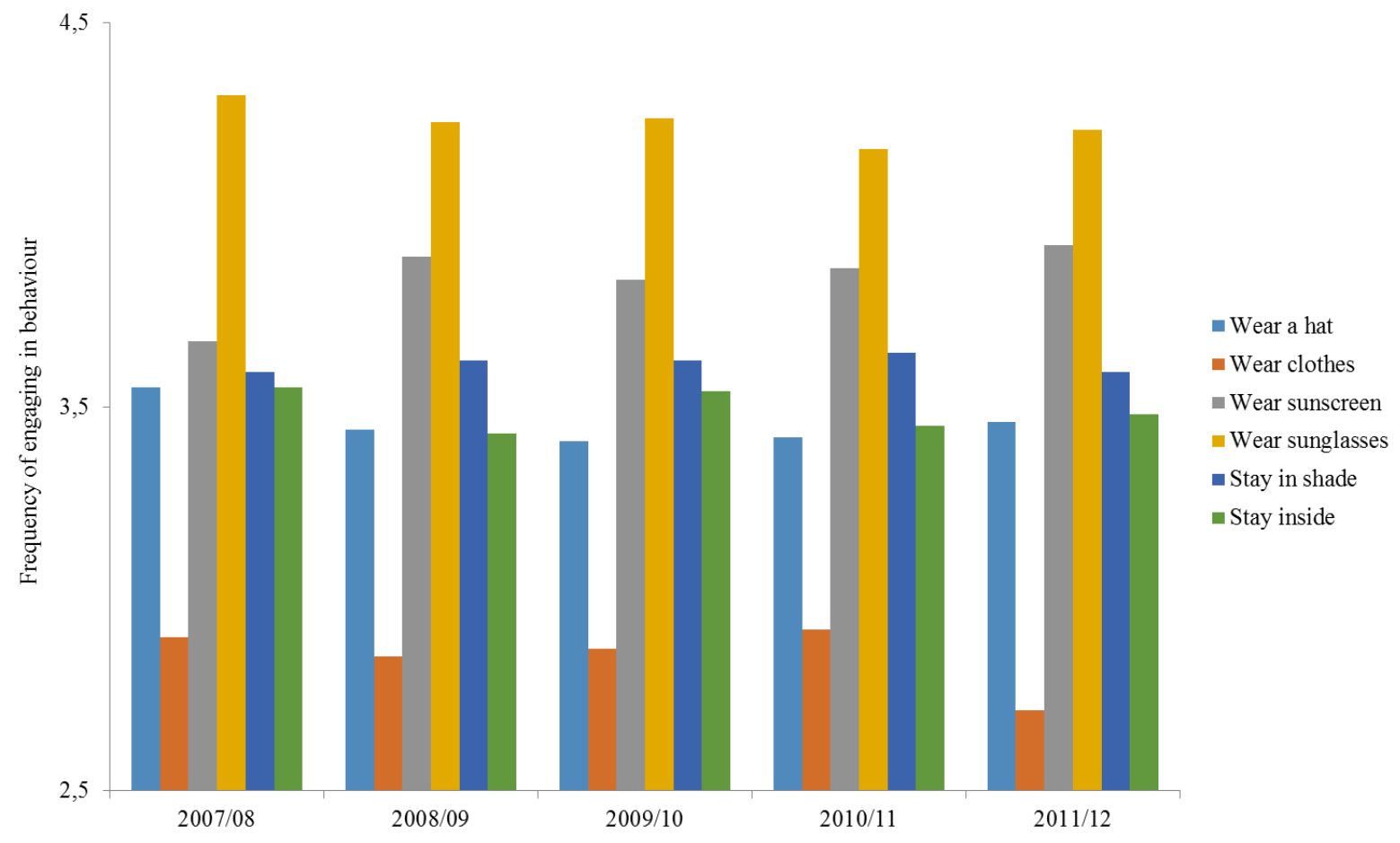

